\title{
Nutritional status in adolescent girls: Attempt to determine its prevalence and its association with sociodemographic variables
}

\author{
Smitha Malenahalli Chandrashekarappa ${ }^{1}$, Narayana Murthy Mysuru Ramakrishnaiah ${ }^{1}$, Renuka Manjunath ${ }^{1}$
}

\begin{abstract}
Objective: To determine the prevalence of malnutrition among adolescent girls and to assess the association of nutrition with sociodemographic variables.

Methods: A cross-sectional study was conducted among adolescent girls aged 16-19 years. Data regarding sociodemographic variables were collected by administration of a prestructured, pretested questionnaire. Height and weight were measured by standardized techniques in a sample of 700 adolescents. BMI was calculated. IBM SPSS Statistics version 22 was used to determine proportions and for chi-square analysis, independence tests, and binary logistic regression.
\end{abstract}

Results: We found $36.2 \%$ of adolescent girls were malnourished, among whom $33.7 \%$ were obese and $66.3 \%$ were undernourished.

Conclusion: Age and education of the mother and father were found to be significantly associated with malnutrition.

Keywords: Adolescent girls; nutrition; malnutrition; BMI; sociodemographic variable

\section{Introduction}

Adolescence represents the transition from childhood to adulthood. Often addressed as teens, adolescents are young people aged between 10 and 19 years [1]. They constitute more than $22 \%$ of India's population, and adolescence is a period of rapid physical, sexual, and psychological growth. Between 2010 and 2025 the global population of girls aged 10-19 years is forecast to grow by more than 23 million [2].

Biological, psychosocial, and cognitive changes that begin during puberty and continue throughout adolescence directly affect nutritional status and nutritional needs. Adolescents experience dramatic physical growth and development during puberty, which in turn will appreciably increase their requirements for energy, protein, and many vitamins and minerals. The increased need for energy and nutrients among adolescents combined with increasing financial independence, increasing need for autonomy when making food choices, and immature cognitive abilities will put them at nutritional risk [3]. Malnutrition further has lifelong implications in the form of increased infection and reduced academic performance, and even affects future generations by increasing the chances of birth of an underweight baby if the mother is malnourished. Hence improving adolescents' nutrition is an investment for the future. This age also forms an opportunity to correct dietary habits and set right the nutritional deficiencies and hence prevent nutritionrelated chronic diseases later in life. For all this to happen the first step would be to know the prevalence of and factors contributing to
1. Department of Community Medicine, JSS Medical College, Mysore, Karnataka 570017, India

CORRESPONDING AUTHOR:

Smitha Malenahalli Chandrashekarappa

Department of Community Medicine, JSS Medical College, Mysore, Karnataka 570017, India Tel.: +91-89719599555

E-mail: smithu.mc@gmail.com

Received 28 June 2016; Accepted 10 October 2016 
malnutrition. Studies conducted in India have shown the prevalence of undernutrition to be greater than $24 \%$ and that of overweight to be greater than $9 \%$. With limited studies and data available in southern India, this study was conducted to find the prevalence of malnutrition among adolescents and its association with various sociodemographic variables.

\section{Research questions}

- What is the prevalence of malnutrition among adolescent girls in the age group of 10-19 years in Mysuru District of Karnataka, India?

- Is there an association of the age, education of the adolescent, presence of siblings, background (urban or rural), place of residence, type of family, birth order, socioeconomic status, education of the father, and education of the mother with adolescent nutritional status?

\section{Objectives}

- To estimate the prevalence of malnutrition in adolescent girls.

- To determine the sociodemographic variables predisposing to malnutrition.

\section{Methodology}

This is a cross-sectional study conducted for 1 year in adolescent girls aged between 16 and 19 years. Estimation of the sample size was done with the formula $n=z p q / l^{2}$, where $z=3.84, p$ is the prevalence of malnutrition (from a previous study), $q=1-p$, and $l$ is the relative precision: that is, $15 \%$ of $p(20)$ is 3 . The sample size of 683 was rounded to 700 , and data were collected from the sample. Multistage sampling was done:

- First stage: Listing of all preuniversity and degree colleges in the city of Mysore under JSS Mahavidyapeetha was done, and one college was randomly selected from the list by a lottery method. The first college picked had a huge number of students and so was sufficient to reach the sample size that was estimated, and hence further colleges were not selected. If this had not been so, further selection of colleges would have continued until the sample size of 700 had been met.

- Second stage: In the selected colleges from the first stage, information was collected regarding the number of classes in the first and second years of preuniversity courses and the first and second years of degree courses, and information was also collected on how many of these classes belonged to arts and science. Of them, two classes were selected for each arts and science subject at every level (i.e. first and second years of preuniversity courses and first and second years of degree courses), again by a lottery method.

- Third stage: All the students in the selected classes were included in the study.

Age was recorded in completed years. Nutritional assessment was done by our recording the height and weight of every adolescent by a standardized procedure. The height was recorded with the help of a wall-mounted tape. It was ensured that the participants removed their shoes and that their heels, hips, back, and head touched the wall before the reading was recorded. The height was measured in centimeters. Weight was recorded with a mechanical weighing scale. The participants were requested to remove their slippers and look forward after standing on the machine before the readings were recorded. BMI was calculated as weight in kilograms divided by height in square meters. It was then classified, and further analysis was done.

Most studies have considered National Center for Health Statistics and World Health Organization (WHO) reference standards as cutoffs for BMI classification for adolescents, but in our study Asian-specific adult reference standards for BMI by WHO were adopted for the following reasons:

- A separate standard has not been recommended specifically for Asian adolescents by WHO.

- When National Center for Health Statistics and WHO standards are compared with the standards recommended for Asian adults, those prescribed for adolescents have higher cutoff values.

- As the adolescents included in our study were late adolescents, we are of the opinion that there use would not make much difference considering the adult scales specific for the Asian population.

The nutritional classification considered in our study is given in Table 1. Information regarding the sociodemographic profile was elicited by use of a prestructured, pretested questionnaire. 
Table 1. Nutritional classification

\begin{tabular}{ll}
\hline Classification & BMI $\left(\mathrm{kg} / \mathrm{m}^{2}\right)$ \\
\hline Underweight & $<18.5$ \\
Normal range & $18.5-22.9$ \\
Overweight & $23.0-25.0$ \\
Obese & $>25.0$ \\
\hline
\end{tabular}

The educational level of the parents was obtained and was classified as not educated, completed 10th grade, completed preuniversity course, completed undergraduate course, and completed postgraduate course. The types of family were divided into nuclear, joint, and three-generation families. The socioeconomic status of the family was categorized according to the modified Prasad classification, which was standardized at the time of the study with use of the consumer price index [4].

Information on other independent variables collected included the subject the adolescents were studying, whether they had an urban or a rural background, and the presence of siblings, birth order, and the place of present residence.

\section{Ethics statement}

Confidentiality and voluntariness were the guiding principles of the study. Informed consent was obtained from each study participant. The study was approved by the Ethics Committee of JSS Medical College, Mysore.

\section{Statistical analysis}

The data obtained were coded and entered into IBM SPSS Statistics version 22 and analyzed with it. Data were analyzed by use of descriptive statistics (i.e. percentages) and inferential statistics with use of the chi-square test for qualitative data. The difference in proportions was considered statistically significant when $P \leq 0.05$. Binary logistic regression was done for variables found to have $P<0.25$ on univariate analysis.

\section{Results}

Of the 700 questionnaires, 36 had incomplete information, and hence they were discarded, and the remaining questionnaires, corresponding to 664 participants, were included for analysis. The mean height of the adolescents was $157.0 \pm 10.2 \mathrm{~cm}$ (range $150.0-176.0 \mathrm{~cm}$ ), the mean weight was $50.2 \pm 8.3 \mathrm{~kg}$ (range $32.0-85.0 \mathrm{~kg}$ ), and the mean BMI was $20.2 \pm 3.3 \mathrm{~kg} / \mathrm{m}^{2}$ (range $\left.12.9-39.1 \mathrm{~kg} / \mathrm{m}^{2}\right)$. When the BMI of the adolescents was calculated, it was seen that $36.4 \%$ of them were malnourished and that the remainder had normal BMI (Table 2). Among the malnourished study participants, $33.7 \%$ (82/242) of them had BMI greater than $22.9 \mathrm{~kg} / \mathrm{m}^{2}$, of which $49.2 \%$ (40/82) were pre obese (i.e., they had BMI between 23.0 and $25.0 \mathrm{~kg} / \mathrm{m}^{2}$ ) and the rest $[50.8 \%(42 / 82)]$ were classified as obese with BMI greater than $25 \mathrm{~kg} / \mathrm{m}^{2}$. The remaining $66.3 \%$ (160/242) were underweight, with BMI below $18.5 \mathrm{~kg} / \mathrm{m}^{2}$.

By Chi-square analysis it was found that age $(P=0.049)$, education of the father $(P=0.001)$, and education of the mother $(P=0.045)$ were found to be significantly associated with malnutrition (Table 3 ).

\section{Binary Logistic regression}

Age (adjusted odds ratio $0.827,95 \%$ confidence interval 0.700 $0.978, P<0.05$ ) and education of the father (adjusted odds ratio $0.330,95 \%$ confidence interval $0.213-0.513, P<0.001$ ) were found to be independent predictors of malnutrition (Table 4).

\section{Discussion}

Malnutrition is a social problem in India. While sex discrimination and the low social status of women in rural India are major reasons, low literacy rates and lack of education among girls worsen the situation. In urban women, anemia and malnutrition are largely caused by adverse effects of a modern lifestyle, where career-oriented adolescents have no time to

Table 2. Distribution of malnutrition among the study participants

\begin{tabular}{lllllll}
\hline Status & Age group & & & & Confidence \\
\cline { 2 - 6 } & $\begin{array}{l}16 \text { years } \\
(n=269)\end{array}$ & $\begin{array}{l}17 \text { years } \\
(n=155)\end{array}$ & $\begin{array}{l}18 \text { years } \\
(n=110)\end{array}$ & $\begin{array}{l}19 \text { years } \\
(n=130)\end{array}$ & $\begin{array}{l}16-19 \text { years } \\
(n=664)\end{array}$ & $\begin{array}{l}\text { interval (chi } \\
\text { square) }\end{array}$ \\
\hline Normal BMI $\left(18.5-22.9 \mathrm{~kg} / \mathrm{m}^{2}\right)$ & $150(55.8 \%)$ & $105(67.7 \%)$ & $74(67.3 \%)$ & $93(71.5 \%)$ & $422(63.6 \%)$ & $66.8 \%-67.2 \%$ \\
Malnourished $\left(\mathrm{BMI}<18.5 \mathrm{~kg} / \mathrm{m}^{2}\right.$ or $\left.>22.9 \mathrm{~kg} / \mathrm{m}^{2}\right)$ & $119(44.2 \%)$ & $50(32.3 \%)$ & $36(32.7 \%)$ & $37(28.5 \%)$ & $242(36.4 \%)$ & $31.7 \%-40.7 \%$ \\
\hline
\end{tabular}




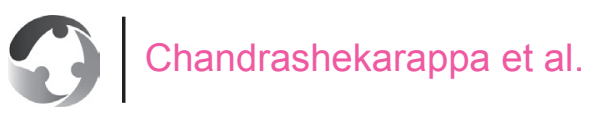

Table 3. Association of sociodemographic variables with nutritional status of the study participants

\begin{tabular}{|c|c|c|c|c|}
\hline \multirow[t]{2}{*}{ Sociodemographic variables } & \multicolumn{2}{|l|}{ Malnutrition } & \multirow{2}{*}{$\begin{array}{l}\text { All participants } \\
(n=664)\end{array}$} & \multirow[t]{2}{*}{$P$-value } \\
\hline & Yes $(n=422)$ & No $(n=242)$ & & \\
\hline \multicolumn{5}{|l|}{ Age (years) } \\
\hline 16 & $150(35.5 \%)$ & $119(49.2 \%)$ & $269(40.5 \%)$ & \multirow[t]{4}{*}{0.049} \\
\hline 17 & $102(24.2 \%)$ & $53(21.9 \%)$ & $155(23.3 \%)$ & \\
\hline 18 & $77(18.3 \%)$ & $33(13.6 \%)$ & $110(16.6 \%)$ & \\
\hline 19 & $93(22.0 \%)$ & $37(15.3 \%)$ & $130(19.6 \%)$ & \\
\hline \multicolumn{5}{|l|}{ Subject } \\
\hline Arts & $206(48.8 \%)$ & $128(52.9 \%)$ & $334(50.3 \%)$ & \multirow[t]{2}{*}{0.336} \\
\hline Science & $216(51.2 \%)$ & $114(47.1 \%)$ & $330(49.7 \%)$ & \\
\hline \multicolumn{5}{|l|}{ Background } \\
\hline Urban & $242(57.3 \%)$ & $152(62.8 \%)$ & $394(59.3 \%)$ & \multirow[t]{2}{*}{0.159} \\
\hline Rural & $180(42.7 \%)$ & $90(37.2 \%)$ & $270(40.7 \%)$ & \\
\hline \multicolumn{5}{|l|}{ Place of residence } \\
\hline Native residence & $258(61.1 \%)$ & $135(55.8 \%)$ & $393(59.2 \%)$ & \multirow[t]{2}{*}{0.189} \\
\hline Hostel & $164(38.9 \%)$ & $107(44.2 \%)$ & $271(40.8 \%)$ & \\
\hline \multicolumn{5}{|l|}{ Siblings } \\
\hline Absent & $90(21.3 \%)$ & $42(17.4 \%)$ & $132(19.9 \%)$ & \multirow[t]{2}{*}{0.136} \\
\hline Present & $332(78.7 \%)$ & $200(82.6 \%)$ & $532(80.1 \%)$ & \\
\hline \multicolumn{5}{|l|}{ Type of family } \\
\hline Nuclear & $270(64.0 \%)$ & $156(64.4 \%)$ & $426(64.2 \%)$ & \multirow[t]{3}{*}{0.944} \\
\hline Joint & $74(17.5 \%)$ & $43(17.8 \%)$ & $117(17.6 \%)$ & \\
\hline Three generation & $78(18.5 \%)$ & $43(17.8 \%)$ & $121(18.2 \%)$ & \\
\hline Birth order & $(n=332)$ & $(n=197)$ & $(n=529)$ & \\
\hline First & $157(47.3 \%)$ & $94(47.8 \%)$ & $251(47.4 \%)$ & \multirow[t]{4}{*}{0.527} \\
\hline Second & $133(40.1 \%)$ & $81(41.1 \%)$ & $214(40.5 \%)$ & \\
\hline Third & $40(12.0 \%)$ & $19(9.6 \%)$ & $59(11.2 \%)$ & \\
\hline Fourth & $2(0.6 \%)$ & $3(1.5 \%)$ & $5(0.9 \%)$ & \\
\hline \multicolumn{5}{|l|}{ Socioeconomic status } \\
\hline Class I & $47(11.1 \%)$ & $27(11.2 \%)$ & $74(11.1 \%)$ & \multirow[t]{5}{*}{0.253} \\
\hline Class II & $121(28.7 \%)$ & $65(26.9 \%)$ & $186(28.0 \%)$ & \\
\hline Class III & $130(30.8 \%)$ & $89(36.7 \%)$ & $219(33.0 \%)$ & \\
\hline Class IV & $92(21.8 \%)$ & $52(21.5 \%)$ & $144(21.7 \%)$ & \\
\hline Class V & $32(7.6 \%)$ & $9(3.7 \%)$ & $41(6.2 \%)$ & \\
\hline \multicolumn{5}{|l|}{ Education of father } \\
\hline Not educated & $81(19.2 \%)$ & $45(18.6 \%)$ & $126(18.9 \%)$ & \multirow[t]{5}{*}{0.001} \\
\hline Completed 10th grade & $151(35.8 \%)$ & $143(59.1 \%)$ & $294(44.3 \%)$ & \\
\hline Completed second year of preuniversity course & $71(16.8 \%)$ & $26(10.8 \%)$ & $97(14.6 \%)$ & \\
\hline Completed under graduate course & $99(23.5 \%)$ & $25(10.3 \%)$ & $124(18.7 \%)$ & \\
\hline Completed postgraduate course & $20(4.7 \%)$ & $3(1.2 \%)$ & $23(3.5 \%)$ & \\
\hline
\end{tabular}


Table 3 (continued)

\begin{tabular}{|c|c|c|c|c|}
\hline \multirow[t]{2}{*}{ Sociodemographic variables } & \multicolumn{2}{|l|}{ Malnutrition } & \multirow{2}{*}{$\begin{array}{l}\text { All participants } \\
(n=664)\end{array}$} & \multirow[t]{2}{*}{$P$-value } \\
\hline & Yes $(n=422)$ & No $(n=242)$ & & \\
\hline \multicolumn{5}{|l|}{ Education of mother } \\
\hline Not educated & $93(22.1 \%)$ & $60(24.8 \%)$ & $153(23.0 \%)$ & 0.045 \\
\hline Completed 10th grade & $117(27.7 \%)$ & $82(33.9 \%)$ & $199(30.0 \%)$ & \\
\hline Completed second year of preuniversity course & $66(15.6 \%)$ & $42(17.4 \%)$ & $108(16.3 \%)$ & \\
\hline Completed undergraduate course & $114(27.0 \%)$ & $48(19.8 \%)$ & $162(24.4 \%)$ & \\
\hline Completed postgraduate course & $32(7.6 \%)$ & $10(4.1 \%)$ & $42(6.3 \%)$ & \\
\hline
\end{tabular}

"n" for Birth order is different as those adolescents with no siblings were not included for analysis. The numbers in the parenthesis indicate the proportions column wise.

Table 4. Binary logistic regression showing independent association of various sociodemographic variables with malnutrition

\begin{tabular}{lllll}
\hline Variable & $\begin{array}{l}\text { Adjusted } \\
\text { odds ratio }\end{array}$ & $P$-value $^{\mathrm{a}}$ & \multicolumn{2}{l}{$\begin{array}{l}\text { Confidence } \\
\text { interval }\end{array}$} \\
\cline { 3 - 5 } & & & $\begin{array}{l}\text { Lower } \\
\text { limit }\end{array}$ & $\begin{array}{l}\text { Upper } \\
\text { limit }\end{array}$ \\
\hline Age & 0.827 & 0.026 & 0.700 & 0.978 \\
Demography & 1.045 & 0.826 & 0.706 & 1.547 \\
Siblings & 1.452 & 0.375 & 0.637 & 3.311 \\
Education of father & 0.330 & 0.001 & 0.213 & 0.513 \\
Education of mother & 0.954 & 0.814 & 0.646 & 1.410 \\
Socioeconomic status & 1.003 & 0.989 & 0.688 & 1.461 \\
Place of residence & 1.234 & 0.480 & 0.648 & 1.302 \\
\hline
\end{tabular}

take care of their health. Junk food consumption is high, leading to a low iron intake, especially in urban areas.

In the present study, when the BMI of the adolescents was calculated, it was seen that $36.4 \%$ of them were malnourished, and the remainder had normal BMI.

Overall, 24.1\% (160/664) of the study population was undernourished. This finding is similar to that of the study by Bhattacharyya and Barua [5] conducted in Dibrugarh, Assam, which showed a prevalence of $25.7 \%$, the study by Srivastav et al. [6] conducted in Gautam Buddh Nagar in Uttar Pradesh [6], which showed a prevalence of $24 \%$, the study by Bovet et al. [7] conducted in Seychelles, which showed a prevalence of $21.2 \%$, the study by Alam et al. [8] conducted in Bangladesh [8], which showed a prevalence of $26 \%$, and the study by Fokeena and Jeewon [9], which showed a prevalence of 27\% [9]. However, a study conducted in Wardha by Maliye et al. [10] showed a higher prevalence of $57 \%$. The difference may be due to the use of different references as cutoffs in different studies. It may also be due to the difference in the age groups of the study participants as we included only late adolescents, and the variation in social, cultural, environmental, and economic factors, which play a very important role in nutrition.

The prevalence of overweight in the study was $12.3 \%$. The finding is similar to that of the study conducted in Davangere, Karnataka, by Kumar et al. [11], which showed a prevalence of $8.82 \%$ [11]. However there are several other studies [12-15] where the prevalence of obesity ranges from $14.2 \%$ to $29.18 \%$. As already mentioned, this may be attributed to the difference in the age groups considered in the studies and variation in the geographical, sociocultural, and economic factors. Another factor might be increased consciousness about maintaining their BMI in the adolescents included in our study as they were all late adolescents, whereas most other studies included study participants aged 10-19 years. A few studies [12, 13] have shown very high prevalence compared with our study as they were conducted in an affluent population. A study conducted in rural Bangladesh by Alam et al. [8] showed the prevalence of obesity to be $0.3 \%$. This low prevalence may be due to the rural background of the adolescents, where relatively less consumption of junk food is seen and they are often involved in daily house activities compared with the sedentary lifestyle of urban adolescents, which reduces their risk of overweight.

Further analysis related to association of nutritional status with various sociodemographic variables showed that age, education of the father, and education of the mother were significantly associated with malnutrition, and binary logistic 
regression showed that age and education of the father had an independent direct association with malnutrition. Age was also found to be significantly associated with malnutrition. Adolescents aged 18 and 19 years formed the major portion of those who were malnourished in our study. This may be due to better access to junk food and peer pressure as age progresses. This was similar to Ghosh et al. [14] findings and a study conducted in Davangere by Kumar et al. [11] which showed that the prevalence of obesity increased with age. Among the malnourished adolescents, there was no statistically significant association with residence. However, those belonging primarily to urban areas had a higher proportion of malnutrition, the reason for which may be earlier access to junk foods and sedentary lifestyle. This finding is similar to that of Alam et al. study conducted at Bangladesh [8]. Those residing with their families formed a major portion of those with malnutrition than those residing in hostels. This may be due to the care taken to provide nutritious food to the students at hostel setting and constant monitoring of their dietary habits. Adolescents with siblings contributed majorly to the prevalence of malnutrition . In relation to Birth order though no statistical association was seen, malnutrition was in higher proportion among those who were born second or later. This can be attributed to the economic burden after the birth of the second child and may also due to gender issues which needs further evaluation. In Bhattacharyya and Barua [5] study there was a significant association seen between family size and malnutrition. In the present study no association was seen between socio-economic status and malnutrition. The reason may be various government programs and schemes such as the midday meal program and Integrated Child Development Services program, which takes care of the poorest of the poor child's nutrition requirement. In the studies by Kotian et al. [16] conducted in South Karnataka [16], Ghosh et al. [14] conducted in Kolkatta, and Guo et al. [13] conducted in China it was seen that as the socioeconomic status increased there was increased risk of overweight, whereas in the study by Fokeena and Jeewon [9] conducted in Mauritius the prevalence of malnutrition increased as socioeconomic status reduced. Further adolescents having better educated parents showed higher prevalence of malnutrition. This was found to be statistically significant as well. This may be due to reason that as the education improves the chances of both parents working is also higher. Hence there might be loss of vigilance on the regular dietary intake of children and their eating habits. The findings are different from that of Bhattacharyya and Barua [5] study conducted in Assam and by Amin et al. [17], where it is seen that most mothers of adolescents with obesity had a lower educational level.

Our study differs from other studies of a similar kind in that here efforts were made to identify the prevalence of malnutrition in the vulnerable girl population, and the sample size was large, which contributed to increasing the power of the study. In addition, the study tried to find the association of sociodemographic variables such as birth order, presence of siblings, place of residence of adolescents, and their education with adolescent nutrition, which was not done in other studies.

Nonetheless, there is a limitation in that other than BMI no other parameter was measured to determine the nutritional status of adolescents, because of time constraints.

\section{Hypothesis generated}

The age of the adolescent and the father's education are important determinants of nutritional status of adolescents.

\section{Acknowledgments}

We acknowledge all the adolescents, principals, and lecturers of JSS Women's College who helped us conduct this study and also the entire Department of Community Medicine, JSS Medical College, for continuous support and encouragement.

\section{Conflict of interest}

The authors declare no conflict of interest.

\section{Funding}

This research received no specific grant from any funding agency in the public, commercial, or not-for-profit sectors.

\section{Significance statement}

This article contributes to the field of adolescent nutrition and also adds to the understanding of socio-demographic variables that might be contributing to malnutrition in the age group between 16-19 years (late adolescence). Many countries, including India, have introduced nutritional programs for the improvement of nutrition in adolescents. Such studies like ours would 
help to evaluate the progress made by such programs, and also by identifying the factors contributing towards malnutrition, would help the planning and implementation of better programs towards specific target groups. Since adolescents form the future of any country, focusing on adolescent nutrition, which has major health implications in the life cycle of an individual, is the need of the hour, more so when it comes to developing countries.

\section{References}

1. World Health Organization. WHOI adolescent development [Internet]. 2013. WHO. [cited 2014 Oct 11]. Available from: www.who.int/maternal_child_adolescent/topics/adolescence/ dev/en/.

2. Central Intelligence Agency. The world factbook [Internet]. 2014. [cited 2014 Oct 11]. Available from: www.cia.gov/library/ publications/the-world-factbook/geos/is.html.

3. Stang J, Story M. Adolescent growth and development. Guidelines for adolescent nutrition services. Minneapolis: Center for Leadership, Education and Training in Maternal and Child Nutrition, Division of Epidemiology and Community Health, School of Public Health, University of Minnesota; 2005. pp. 1-8.

4. Dudala SR, Reddy AK, Prabhu GR. Prasad's Socio-economic status classification- an update for 2014. [Internet]. 2014. [cited 17 June 2016]. Available from: http://oaji.net/articles/2014/624-1406827028.pdf.

5. Bhattacharyya H, Barua A. Nutritional status and factors affecting nutrition among adolescent girls in urban sum of Dibrugarh, Assam. Community Med 2013;4(1):35-9.

6. Srivastav S, Mahajan H, Grover VL. Nutritional status of the government school children of adolescent age group in urban areas of district Gauthambudh-Nagar, Uttar Pradesh. Community Med 2013;4(1):100-3.

7. Bovet P, Kizirian N, Madeleine G, Blössner M, Chiolero A. Prevalence of thinness in children and adolescents in Seychelles: comparision of two international growth references. Nutr J 2011;10(1): 1 .

8. Alam N, Roy SK, Ahmed T, Ahmed AS. Nutritional status, dietary intake, and relevant knowledge of adolescent girls in rural Bangladesh. J Health Popul Nutr 2010;28(1):86.

9. Fokeena WB, Jeewon R. Is there an association between socioeconomic status and body mass index among adolescents in Mauritius? Sci World J 2012;2012:1-9.

10. Maliye C, Deshmukh P, Gupta S, Kaur S, Mehendale A, Garg B. Nutrient intake amongst rural adolescent girls of Wardha. Indian J Community Med 2010;35(3):400-2.

11. Kumar S, Mahabalaraju DK, Anuroopa MS. Prevalence of obesity and its influencing factor among affluent school children of Davangere city. Indian J Community Med 2007;32(1):15-7.

12. Goyal J, Parmar I, Patel B, Kumar N, Shah V. Determinants of overweight and obesity in affluent adolescent in Surat city, South Gujarat region, India. Indian J Community Med 2011;36(4):296-300.

13. Guo X, Zheng L, Li Y, Yu S, Sun G, Yang H, et al. Differences in lifestyle behaviors, dietary habits, and familial factors among normal-weight, overweight, and obese Chinese children and adolescents. Int J Behav Nutr Phys Act 2012;9:120.

14. Ghosh A. Explaining overweight and obesity in children and adolescents of Asian Indian origin: the Calcutta childhood obesity study. Indian J Public Health 2014;58(2):125-8.

15. Nawab T, Khan Z, Khan I, Ansari M. Influence of behaviora determinants on the prevalence of overweight and obesity among school going adolescents of Aligarh. Indian J Public Health 2014;58(2):121-4.

16. Kotian MS, Kumar SG, Kotian SS. Prevalence and determinants of overweight and obesity among adolescent school children of South Karnataka, India. Indian J Community Med 2010;35(1):176-8.

17. Amin TT, Al-Sultan AI, Ali A. Overweight and obesity and their association with dietary habits, and sociodemographic characteristics among male primary school children in Al-Hassa, Kingdom of Saudi Arabia. Indian J Community Med 2008;33(3):172-81. 